A Guide to Goal Setting in TEA:

A Worked Example Considering $\mathrm{CO}_{2}$ Use in the Domestic Heating Sector 
Published April 2020

This work is available under DOI 10.3998/2027.42/154988

and can be downloaded via http://hdl.handle.net/2027.42/154988

\section{Main Contributors}

The University of Sheffield

Stephen McCord

Ana Villa Zaragoza

Peter Styring

\section{Further Contributions}

Institute for Advanced Sustainability Studies e.V. Potsdam

Lorenzo Cremonese

Till Strunge

Global $\mathrm{CO}_{2}$ Initiative

Volker Sick 


\section{Foreword}

Climate change is one of the largest challenges of our time. It is proven that excess amounts of carbon dioxide that humanity has added to the atmosphere plays a key role, and left unaddressed, this will alter ecosystems and fundamentally change life as we know it. Under the auspices of the UN Framework Convention on Climate Change and through the Paris Agreement, there is a commitment to keep global temperature increase to well below two degrees Celsius. Meeting this goal will require a variety of strategies including increased renewable power generation and broad scale electrification, increased energy efficiency, and carbon-negative technologies. Carbon-negative technologies serve two purposes, as a climate mitigation tool near term, and to create a new carbon economy that recycles carbon over the long term- balancing emissions of still essential industrial sectors such as cement and steel. Overall, carbon-negative technologies are a valuable strategy in an overall portfolio of approaches to stabilize the atmospheric carbon dioxide concentration at a level that supports human life on Earth.

Increased attention is being paid to the notion that carbon dioxide can become a valuable resource instead of being a waste product with severe negative consequences to the earth's climate. New technologies, new use cases, interest from the investment community, and growing legislative support poise the use of a carbon dioxide feedstock as a viable economic and societal opportunity.

But not all that glitters is gold! Thorough assessment of the environmental and economic benefits of new technologies is paramount prior to deployment. Transparent and consistent life cycle assessments and techno-economic assessments must provide unbiased information to decision makers to enable sound decisions on investments, deployments, and public support for such.

International demand from government bodies, industry, investors, non-profits, and researchers for harmonized approaches to conduct life cycle assessments and techno-economic assessments for carbon dioxide utilization led us to coordinate and fund an international effort to develop and disseminate Guidelines for TEA \& LCA for $\mathrm{CO}_{2}$ Utilization. First published in 2018, these Guidelines have found widespread attention and use. A growing list of case studies, and worked examples, is made available to illustrate how to use these Guidelines.

We hope that this case study will be useful to you and we will be grateful for any feedback! 


\section{Abbreviations}

BAU Business as usual

BEIS Department for Business, Energy \& Industrial Strategy

DME Dimethoxyethane

DUKES Digest of UK energy statistics

ECUK Energy Consumption in the UK (report)

EU28 European Union 28 countries (as of 2019)

FOAK First of a kind

GWh gigawatt hour

kWh kilowatt hour

LCA Life Cycle Assessment

Mtoe Mega tonnes of oil equivalent

MWh megawatt hour

NOAK nth of a kind

OFGEM Office of Gas \& Electricity Markets

PtG Power to gas

PtX $\quad$ Power to $X$

R\&D Research \& development

SAP Standard assessment procedure

TDCV Typical domestic consumption values

TEA Techno-Economic Assessment 


\section{Contents}

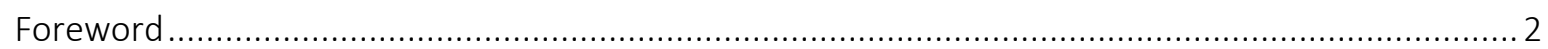

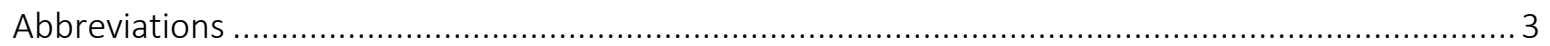

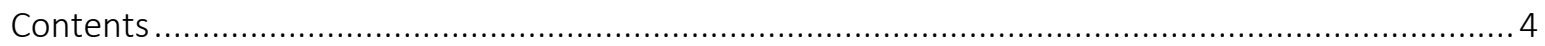

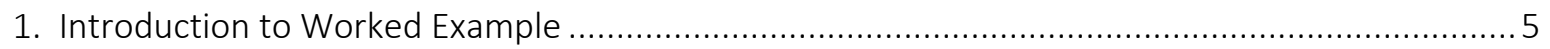

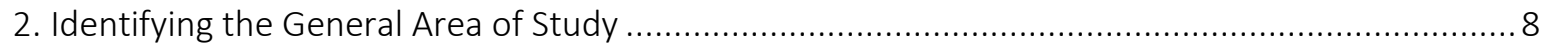

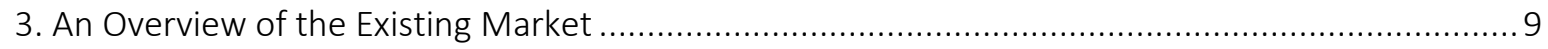

Setting a Goal in Accordance with the Guidelines..................................................... 19

4. Inventory Impacts on Goal Achievement: Advice for Using Existing Studies or Inventories for New

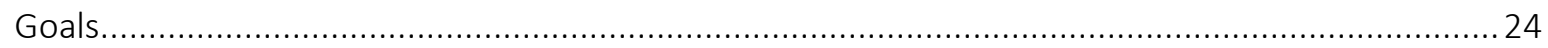

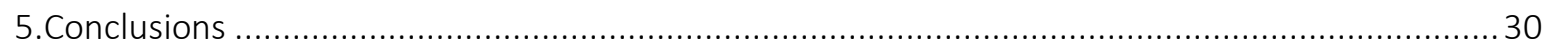

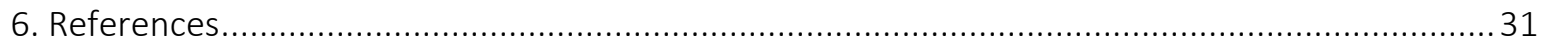

This worked example is part of a series of worked examples produced in support of the "TechnoEconomic Assessment \& Life Cycle Assessment Guidelines for $\mathrm{CO}_{2}$ Utilization". These guidelines, further worked examples and other associated documents can be found online at:

https://deepblue.lib.umich.edu/handle/2027.42/145423

More details on the Global $\mathrm{CO}_{2}$ initiative can be found online at:

https://www.globalco2initiative.org/ 


\section{Introduction to Worked Example}

\section{What is the importance of setting the correct goal for a study?}

Setting the correct goal is vital to ensure that the outcomes of the study reflect what is needed or wanted from the study commissioner (who may or may not be the same party as the practitioner). For the practitioner, the goal will impact every subsequent stage of the study and the methodological choices made in each of these: what to include within the scope, what sort of scenarios should be considered, what is the most suitable functional unit, what needs to be included within the inventory and what sort of indicators need to be calculated to give an accurate assessment to achieve the goal.

The goal of study is ultimately derived from the aims of the study commissioner and as such should be considered as one of the most "open ended" parts of the TEA framework. It is for this reason why care must be taken to ensure adherence to the guidelines, given that:

- A well-described goal helps prevent incorrect comparisons between assessments by including key information on the study context, intended application and the studies limitations

- A well-described goal allows for easy assessment by any reader on how useful a particular study is for achieving their aims or answering their specific research question

Why does the aim of the Commissioner matter?

The aim of the commissioner may be broad e.g. "the aim of the commissioner is to assess how sustainable replacing existing fossil derived methanol with $\mathrm{CO}_{2}$ derived methanol in the UK within 5 years". Given there are more metrics to sustainability than economics and technical feasibility it is likely the commissioner will seek other forms of assessments such as a life cycle assessment or an environmental risk assessment to address elements not covered in a TEA.

Alternatively, the aim can be narrower in which a TEA study \& its output may wholly achieve the desired outcome - e.g. "the aim of the commissioner is to assess the financial viability of constructing a $\mathrm{CO}_{2}$ derived methanol plant in the UK within 5 years". In this example, the aim is stated to be purely economic in nature, making it plausible to consider TEA only.

In either case, the setting of a goal for a TEA study should be seen as a balance between two elements:

1. Achieving (or assisting in the achievement of) the aim of the study commissioner

2. Ensuring the goal that can be achieved with the inventory available

What is the process of setting a goal?

As such, the process of setting a goal should not be viewed as something static, but as something to be reviewed and adjusted as required. Ensuring that goal is both achievable and relevant is the responsibility of both the commissioner and the practitioner. Care should be taken to facilitate any relevant discussion during this potentially iterative process.

The Guidelines in part B1 state that Goal shall include the items listed in Figure 1. In many cases the goal is firstly written in a more generic fashion i.e. "the aim of the commissioner is to assess how sustainable replacing existing fossil derived methanol with $\mathrm{CO}_{2}$ derived methanol in Europe within 5 years". However, this leaves a lot of questions open to the reader, for example will the methanol be used as a fuel or chemical (this could impact on financial incentives) or where exactly is the plant located 
(impacts on of costs of energy and transportation) or when does the 5-year period start? Therefore, the more specific the goal can be the more helpful it is to the reader, practitioner and commissioner.

Guideline B. 1 - Goal definition

\begin{tabular}{|cl}
\hline Shall & 1) State the study context (especially comparison to what, location, time horizon, scale \\
and involved partners) \\
\\
2) State the intended application and reasons for the study \\
3) State the target audience for the study \\
4) State commissioners and authors of the study \\
Should & 5) State limitations in the usability from assumptions or methods \\
May &
\end{tabular}

Figure 1 - Guideline B1 taken from [1]

What are the pitfalls I should be aware of?

A particular issue that can arise is the utilisation of data in the inventory that may be correct but lacks relevance to the goal - for example, a common issue is the use of costing data that is not fitting for the desired location (for materials, labour). Poor inventory control in these instances can ultimately lead to inaccurate outputs with regards to fulfilling the initial goal. In some cases, it may be that more accurate data is not available, and as such a decision needs to be made as to whether to continue the study with best available data (and an accepted increase in uncertainty in the results) or end the study prematurely without achieving the goal/aim.

TEA is a general assessment framework, one that can be applied to achieve a variety of goals as evidenced in the guidelines by table 2 (section B.3) [1] which gives an overview of common perspectives.

Whilst this offers obvious advantages, it does lead to a potential pitfall in ensuring the correct goal is set for the target audience (whether this be the commissioner, practitioner or any other third party) to ensure their needs are met.

A further issue identified in the guidelines is one of comparability, the guidelines state "that comparisons between existing studies are challenging, especially when comparing technologies of varying disciplines, markets and technology maturities". The guidelines address this issue through guideline B1, which mirrors the guiding principles used in LCA studies. Also acknowledged in the guidelines is that compliance with this guidance will result in the production of assessment goals that differ from those commonly included in studies currently - to provide further clarity on this illustrative examples from varying perspectives are included in this document. 
Identified Pitfalls:

- Failure of the goal to meet the aim of the commissioner (addressed through communication and the production a well-structured goal statement)

- Failure to ensure the goal of the study is accurately met (addressed through inventory control)

- Failure to make a clear goal statement leading to difficulty in identifying comparable studies (addressed through the production of a well-structured goal statement)

What is the purpose of this worked example?

To minimise the risk from these identified pitfalls, this worked example will provide additional illustrative guidance for study commissioners and for practitioners in the setting of a suitable goal and subsequent scope, scenarios and functional units.

In this worked example we explore an identified area of potential deployment for $\mathrm{CO}_{2}$ utilisation technologies (namely the domestic heating sector) and show how the same identified issue/problem statement can be used to derive differing research question \& goals dependent on perspective.

NOTE: In the "Making Sense of TEA \& LCA Studies for $\mathrm{CO}_{2}$ Utilization" report decision trees are available for use to help guide readers on what action they should take to meet their assessment needs. Three case types are identified:

- Case A where the commissioner needs to commission one or more new studies

- Case B1 where the commissioner can use one existing study

- Case B2 where the commissioner can use and compare multiple existing studies

This worked example can be used in conjunction with any of these case types given that all three require the commissioner to either: derive a goal for a study to be commissioned; communicate effectively with a practitioner to ensure a correct goal is set; or understand whether an existing study has a goal statement that meets their requirements 


\section{Identifying the General Area of Study}

For the purpose of this worked example it is important to primarily identify a general area of study from which several research questions can be asked. Given the nature of the guidelines, there is a need to identify an area in which $\mathrm{CO}_{2}$ utilisation technologies could potentially be deployed to resolve the derived problem statement.

\section{Area of study for this example}

In June 2019, the UK became the first major economy to pass laws committing itself to "end its contribution to global warming by 2050" [21]. To meet this challenging goal significant changes need to be made to several existing emissions intensive sectors - with upwards of $80 \%$ of the UKs $\mathrm{CO}_{2}$ emissions being attributed to energy use [22].

Whilst some sectors have seen a marked reduction in emissions, such as electricity generation where carbon intensity per kWh has decreased drastically in recent years, others are yet to make significant progress. One sector that is known to be particularly problematic is the domestic heating sector. The provision of heat (predominantly for space heating and hot water production) dominates household energy consumption, with the dominant fuel by market share being natural gas.

With a general issue outlined (the need to reduce fossil $\mathrm{CO}_{2}$ emissions in the domestic heating sector) it is possible to begin deriving research questions various perspectives which can ultimately be transformed into TEA goals.

However, in this worked example a review of elements of the existing domestic heating market will be covered. This shouldn't necessarily be considered as a necessary part of a TEA study and is primarily included here to provide a basis for the illustrative elements of this worked example.

However, it should be noted that Guideline B.1 (Goal definition) does state that the study context must be stated in the goal and therefore in some cases it may be beneficial to include some degree of a market overview for the benefit of the reader of the study. Such an overview can also provide evidence as to why comparison were made, with this especially useful in industries where one clear best available technology (BAT) is not obvious, or varies globally. A good example of the latter would be the current production of hydrogen, in much of the world steam methane reformation (SMR) is the dominant technology, however in China there is a reliance on coal due to the abundance of coal and high gas import prices [2]. 


\section{An Overview of the Existing Market}

In this report the UK domestic heating sector refers to the provision of space heating, the provision of hot water and other miscellaneous uses (such as cooking in some domiciles) to residences of all types. Not included for consideration are the heating demands for commercial properties, public administrated buildings, agriculture or other miscellaneous properties.

Currently the provision of domestic heat (and energy) in the UK is dominated by the use of natural gas. However, given the UK governments current commitment to achieving "net zero" carbon emissions by 2050 [3] there is an obvious need to address the emissions of the sector. Through developing a picture of the existing domestic heating market it is possible to gain an understanding of a current "business as usual" picture alongside an understanding of established and emerging trends in fulfilling functional demand.

\section{Macroscopic Domestic Energy Demand \& Energy Sources}

The Digest of UK energy statistics (DUKES) is an annually published report providing an overview for energy use in the UK as a whole, the most recently published report was released in 2019 utilising data from 2018 [4]. From the DUKES 2019 report:

- Annex table 1.1 of the report shows the aggregate energy balance for the UK in 2018, included are statistics showing total primary energy demand for the UK as 200.1 Mtoe, with this translating to 151.3 Mtoe of final consumption (energy is used in the transformation of primary sources to consumer ready forms, such as the conversion of gas to electricity or oil to petroleum products resulting in the divergence between the figures)

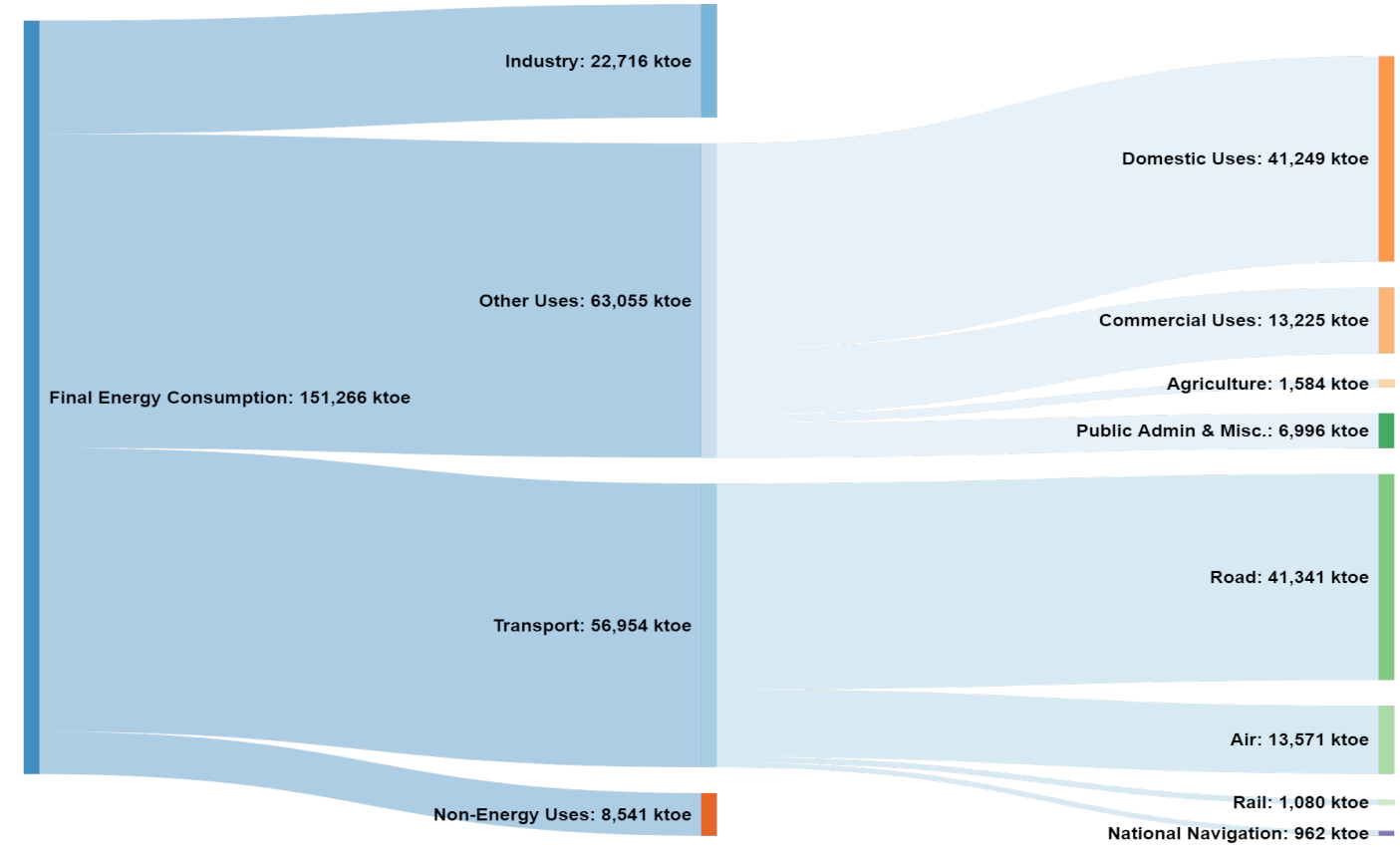

Figure 2 - Final consumption of energy in the UK by sector [4]

- Of this total of 151.3 Mtoe, 26.6 Mtoe of natural gas is consumed to meet domestic demand primarily for space heating and water heating with some also used for cooking - this amounts to $17.6 \%$ of all UK final energy consumption 
- Total primary demand for natural gas in the UK amounted to 75.4 Mtoe with domestic consumption accounting for $35.2 \%$ of this. Of this total primary demand 26 Mtoe is used in "energy transformation" (primarily for electricity generation) with a further 4.9 Mtoe used by the energy industry and around 0.6 Mtoe is lost. This leaves final consumption of natural gas totalling 44.2 Mtoe, with domestic consumption accounting for $60.2 \%$ of this. Figure 3 below shows that domestic demand for natural gas has typically been the dominant sector

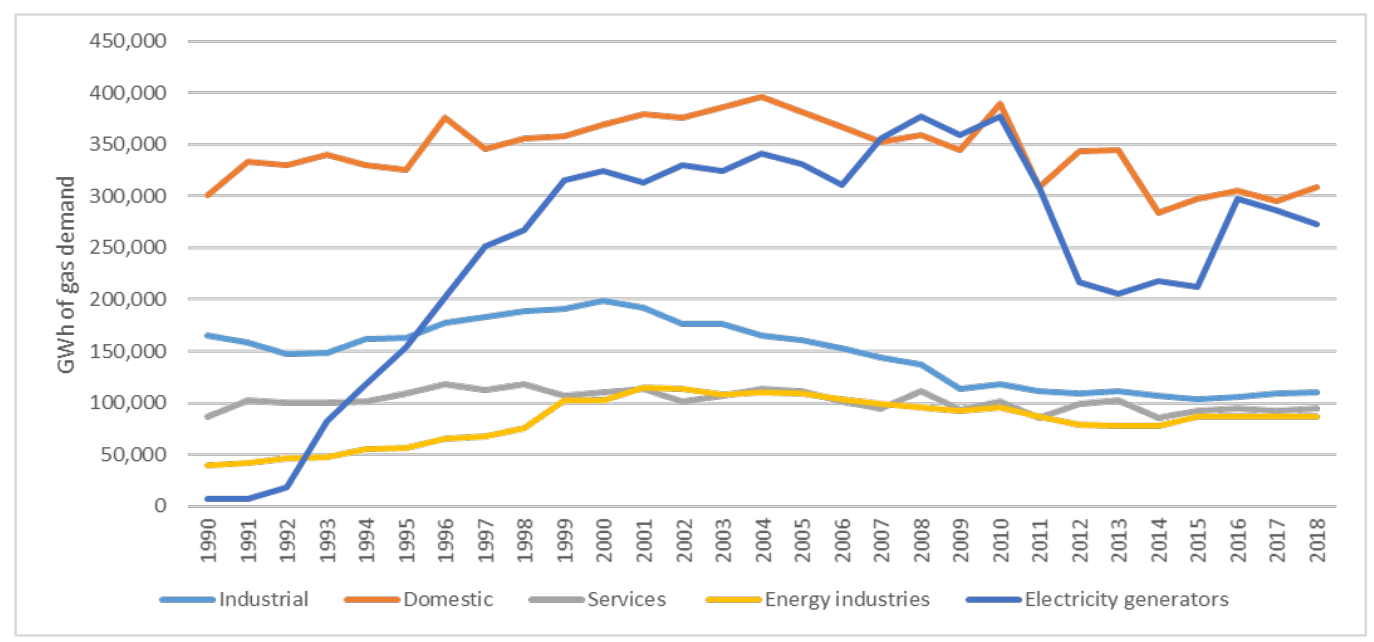

Figure 3 - Primary demand for natural gas [4]

- In summary of the point above - domestic demand for natural gas is the single greatest contributor to UK consumption, even outstripping demand for natural gas to generate electricity

- Domestic energy consumption across all energy sources amounted to $41.2 \mathrm{Mtoe}$, with most of this being consumed in the form of natural gas ( $64.6 \%$ of the total) - second to this is the consumption of electricity at 9 Mtoe (21.8\% of the total)

Further information on domestic sector energy use can be found in the annual Energy Consumption in the UK (ECUK) report [5], also published by BEIS. The 2019 edition, updated to include 2018 figures, includes data on domestic energy trends in the UK for the period 1970 to 2018, with the general trend captured in figure 4 below.

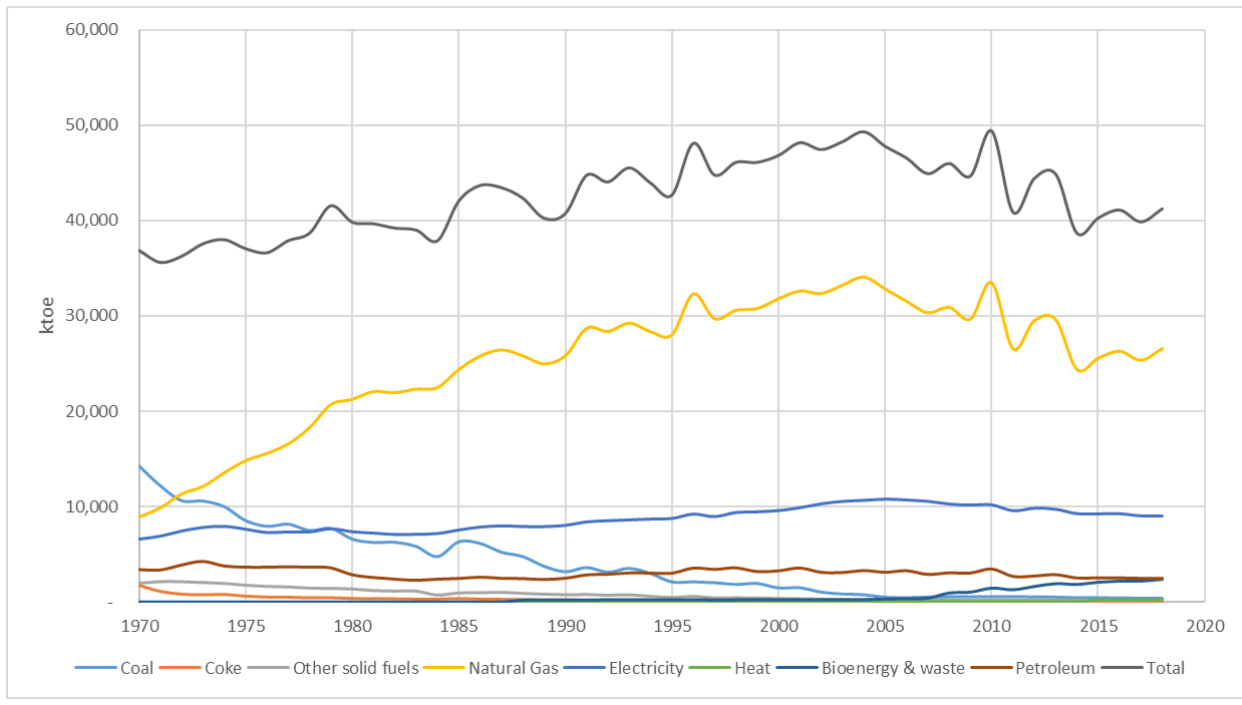

Figure 4 - Trends in domestic energy consumption within the UK 
The figure shows an increasing trend in total energy use peaking in the early 2000s before a general decline after this, even as the population and number of households has continued to grow. According to the ECUK report, this decrease is associated with a marked increase in energy efficiencies in UK households - with this corroborated in a 2013 reported on domestic energy use [6]. This increase in efficiency has been deliver in two areas:

1. Improved appliance efficiency within the home (e.g. boilers, white goods, TVs)

2. Improved thermal efficiency of homes (e.g. double glazing, cavity wall \& loft insulation)

The 2013 housing energy fact file [6] states that energy efficiency has improved in UK homes every decade with the average SAP score (a standardised way to assess housing energy efficiency from 1 to 100) rising from 17.6 in 1970 to 56.7 in 2013.

Figure 5 also shows that on a year-to-year basis there are some minor fluctuations distorting the overall trend. The ECUK report states that this is due to annual temperature variance - typically colder years or those that are impacted by bad weather events (such as the spike in 2010). To account for this temperature corrected data is available from 2002 onwards, shown in figure 5 below alongside the, which shows a more consistent downward trajectory.

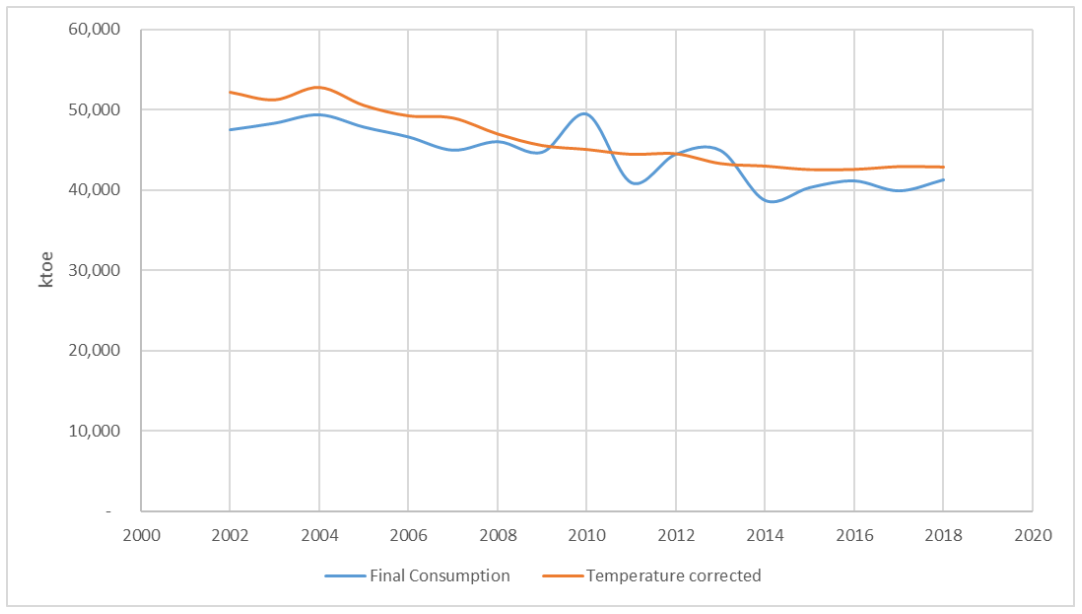

Figure 5 - Total domestic energy consumption and temperature corrected equivalent

Further evidence on the temperature dependent nature on domestic energy consumption in other publications.

Trends in gas consumption in the UK are reported by the UK government in its energy trends series [7]. Part of the series captures quarterly gas demand in the UK, with the data included in figure 6 below. 


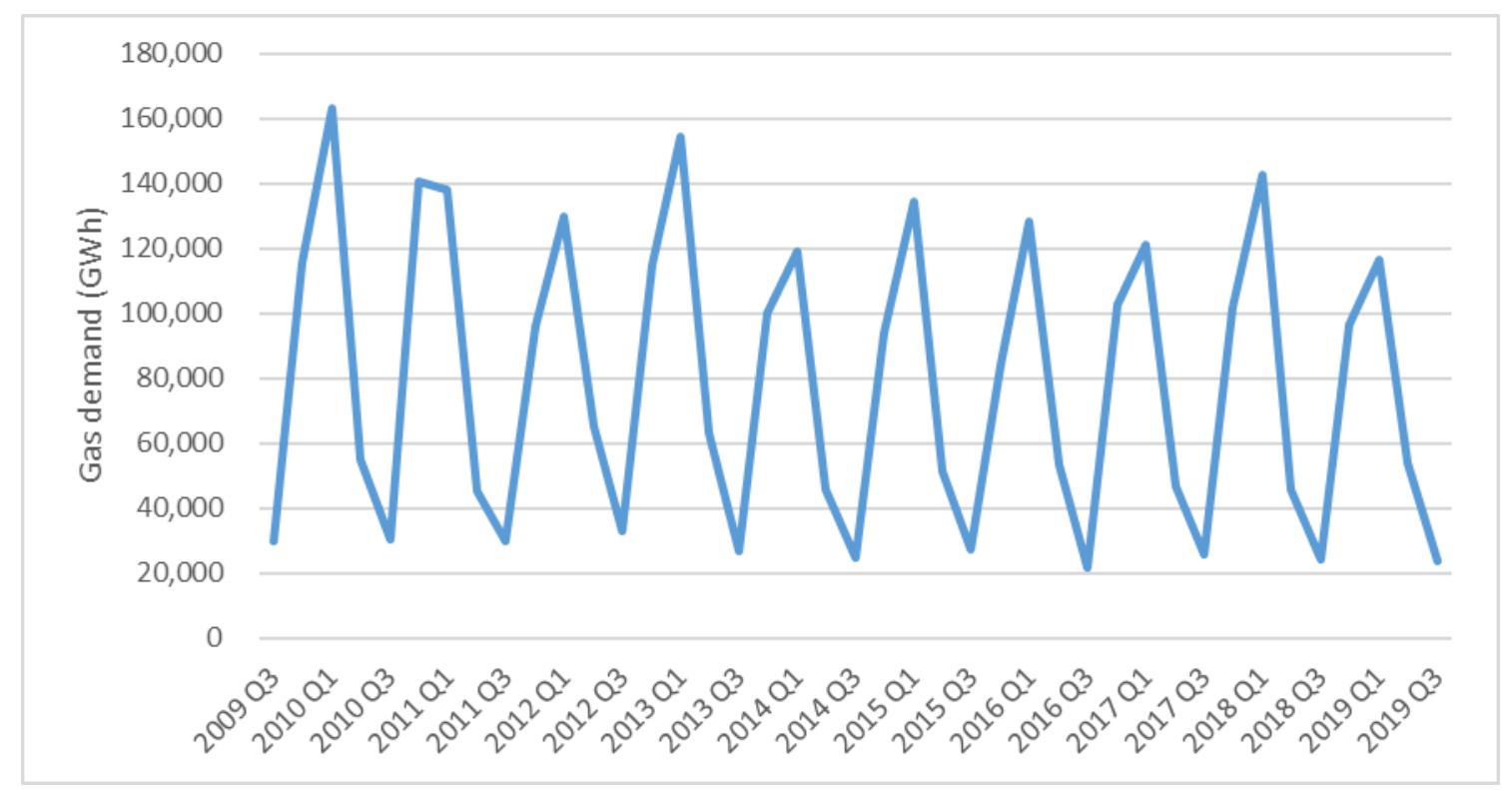

Figure 6 - UK domestic gas demand by quarter, data from [7]

Figure 6 shows a clear seasonal trend over the 10 years of data - domestic gas demand peaks in Q1 (January to March) and troughs in Q3 (July - September). This demonstrates the dominance of space heating (seasonal demand linked to ambient temperature) on domestic gas demand over the use of gas for cooking and hot water (anticipated to be more uniform throughout the year). To further this point, source [6] suggests that typically (from the 1990s onwards) space heating has accounted for between 60 and $70 \%$ of total domestic energy use, as shown in figure 7 .

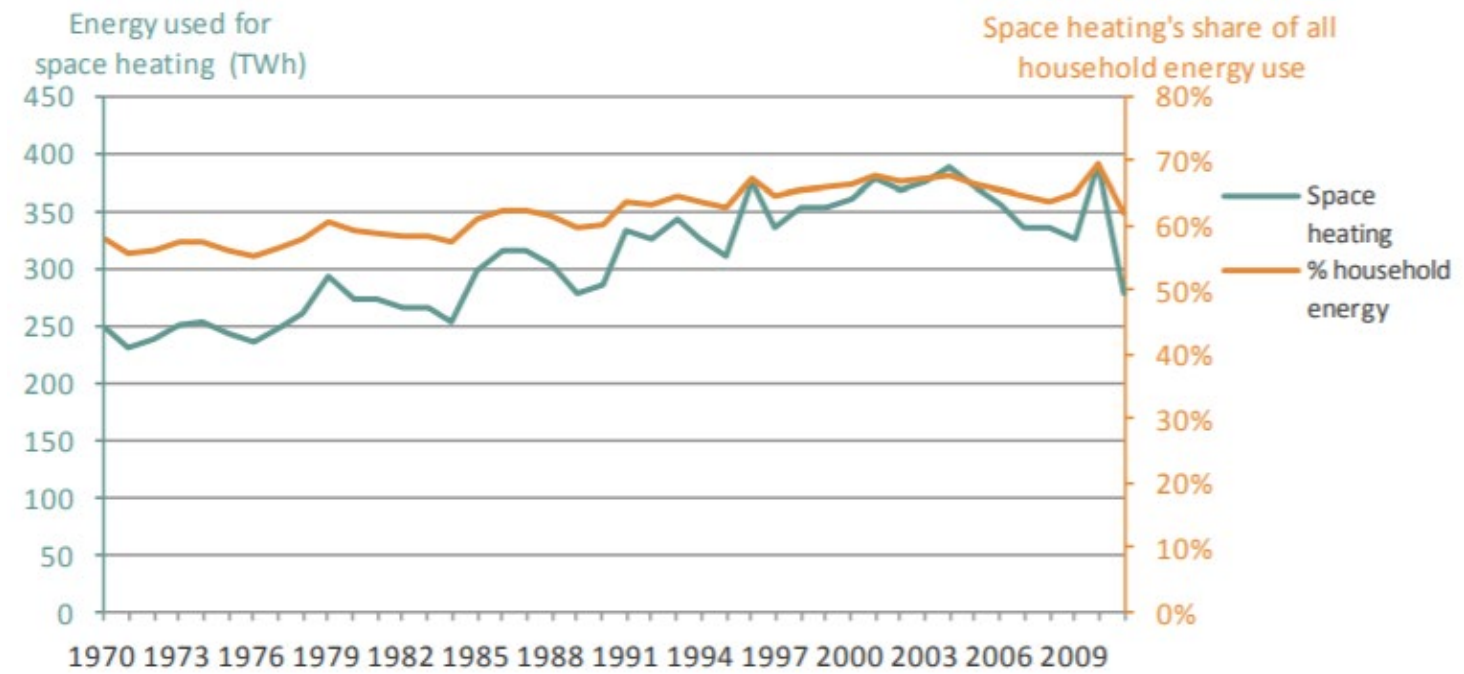

Figure 7 - The contribution of space heating to total UK household energy use, graph taken from [6]

From the same report, the energy demand for hot water provision as a percentage of total is also available, shown in figure 8 below. As the graph shows the percentage share has declined substantially since the 1970s (from a peak of around 30\% to a low of around 15\%) but remains significant. 


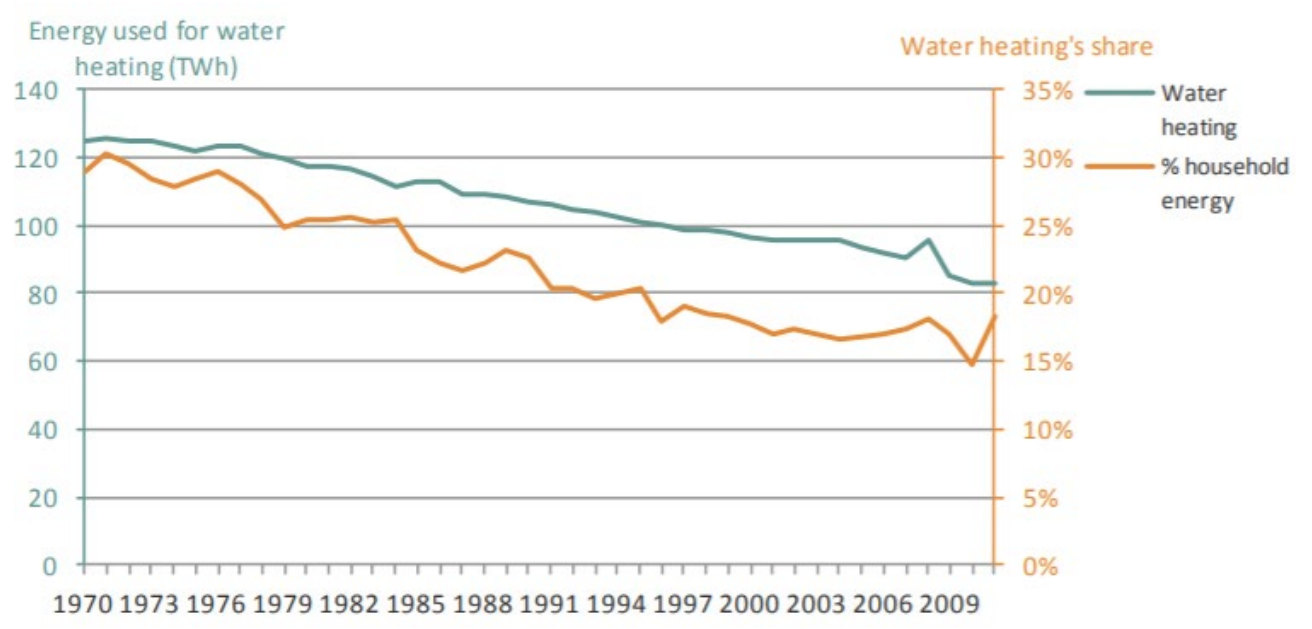

Figure 8 - The contribution of water heating to total UK household energy use, graph taken from [6]

The combined total for hot water and space heating account from the figures above approximately $80 \%$ of total household energy demand.

Alongside seasonal variation daily variation in demand can also be seen, as shown in figure 9 taken from an OFGEM report on decarbonising heat [8]. The figure clearly shows peaks within the day that demonstrate varying levels of demand - as such any technology needs to be able to deal with the rapid upturns and downturns and the range of typical operating conditions.

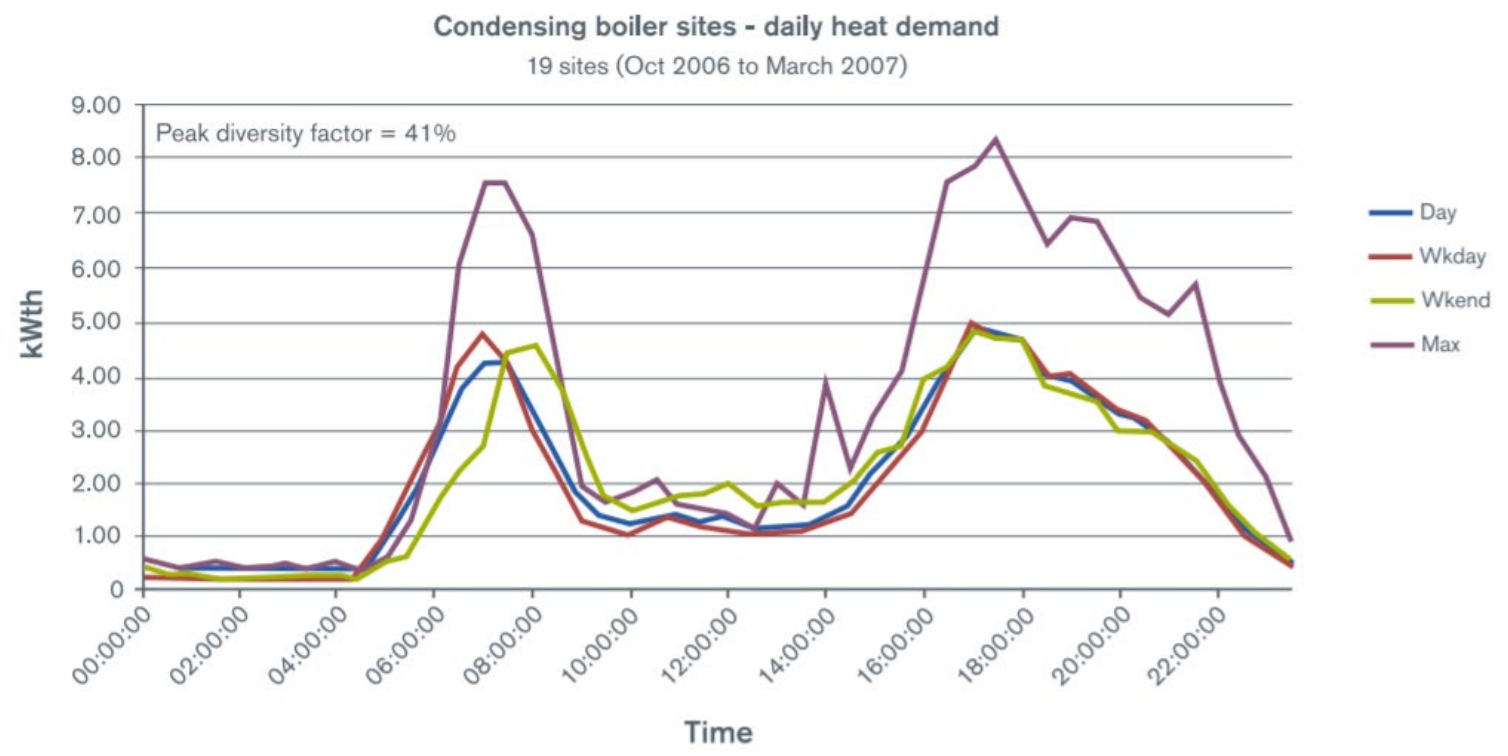

Figure 9 - Heat demand profile for a condensing boiler, taken from [8]

\section{Domestic Energy Demand - Per Household Basis}

Whilst the prior section gives details on market capacity in a broad sense, it does not give much insight into individual homes, the following sections will provide a more detailed breakdown of energy usage and technologies used for heat provision for this purpose.

Whilst somewhat dated, a 2008 study [9] by the Energy Saving Trust into domestic hot water use concluded from a sample of 112 dwellings that UK average hot water on a per dwelling basis use was 
122 litres per day (95\% confidence interval of $\pm 18 \mathrm{~L} /$ day). The mean energy content of this was 16.8 $\mathrm{MJ} /$ day $(95 \%$ confidence interval of $\pm 2.2 \mathrm{MJ} /$ day), a value lower than expected by the authors due to expected higher hot water delivery temperatures that align with best industry best practices.

For a broader overview of gas use domestically in the UK, OFGEM [10] report annually typical domestic consumption values (TDCV) for both gas and electricity. Each TDCV is reported for low-medium-high users, to account for differing demand levels related to living circumstances, the values reported by OFGEM as of January 2020 are:

- Low: 8,000 kWh of gas annually

- Medium: 12,000 kWh of gas annually

- High: $17,000 \mathrm{kWh}$ of gas annually

TDCVs for electricity are also available, with two different user profiles identified by OFGEM dependent on meter type (profile class 1 has fixed rate meters, profile class 2 has Economy 7 variable meters with differing rates for day \& night). The values reported by OFGEM as of January 2020 (current until April 2020) are:

Profile 1

- Low: 1,900 kWh of electricity annually

- Medium: 3,100 kWh of electricity annually

- High: 4,600 kWh of electricity annually

Profile 2

- Low: 2,500 kWh of electricity annually

- Medium: 4,200 kWh of electricity annually

- High: 7,100 kWh of electricity annually

The ECUK report discussed in the prior section [5] also provides data on trends for household consumption of both gas and electricity across the UK, with the trend shown in figure 10 below - both raw data and temperature corrected data are given. It should be noted that the mean average is across all households and does not offer the same level of insight with regards to usage profiles.

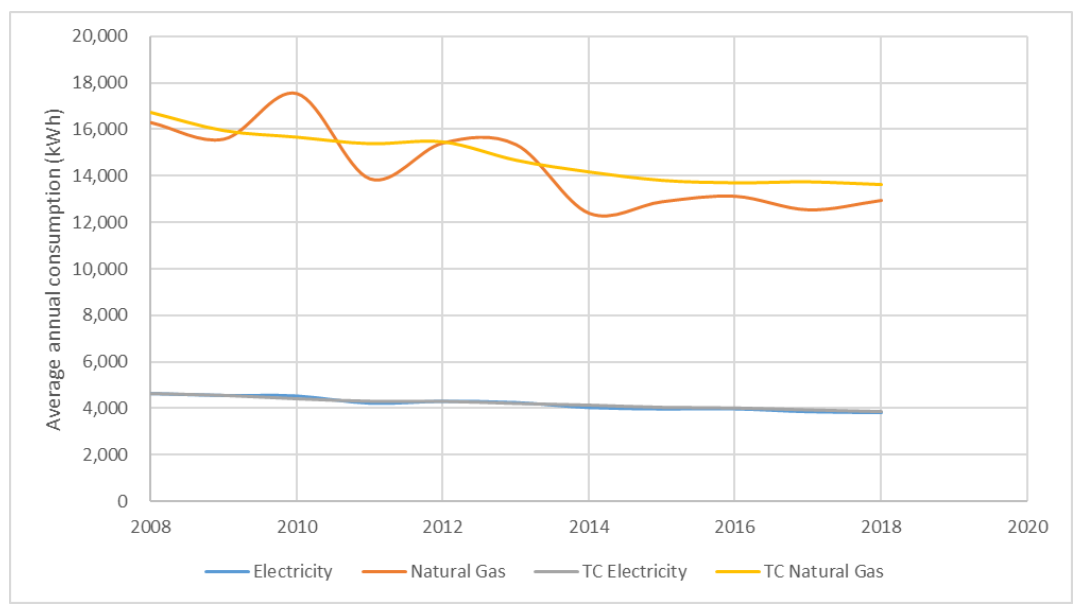

Figure 10 - Average annual household consumption for electricity and natural gas (TC - temperature corrected) 


\section{Domestic Heating Technology Overview}

Statistics on the type of technologies used to provide domestic heat are also collected on a regular basis by the UK government. Data tables associated with the English Housing Survey [11] are available online, with these figures providing a good introduction to the existing state of play.

The statistical tables that support the headline report show:

- Approximately 92\% of English homes had central heating installed, the remaining fraction was split between storage heaters and room heaters (fixed/non-fixed electrical heaters \& fires).

- Approximately $87 \%$ of English homes utilised gas as their main fuel type. Second to this was electricity (around $8.5 \%$ ), followed by oil and solid fuels.

- Approximately $91 \%$ of English homes had hot water provided via the boiler associated with their central heating. The remaining fraction being dominated by immersion heaters.

The English Housing Survey for 2018-19 [11] states that condensing-combination boilers have rapidly become the dominant boiler technology in English homes, accounting for over $50 \%$ of all installed boilers domestically as of 2018. The trends in installation are captured in Figure 11 below, taken from the aforementioned report.

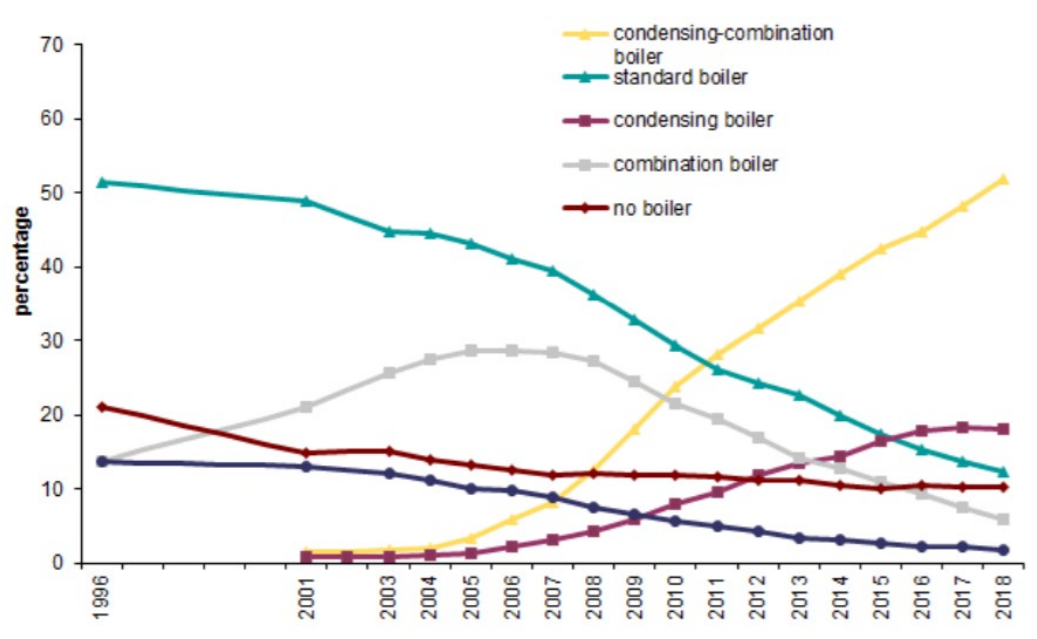

Figure 11 - Trends in domestic boiler types, graph from [11]

The only other boiler classification to see an increasing share of installation to see an increase in the last decade has been the condensing boiler. As of 2018 regulations state that all newly installed boilers have to be condensing in design and as such it is fair to assume that the trends established are likely to continue. Condensing systems utilise the latent heat of vaporisation from the water produced in gas combustion in a secondary heat exchanger to pre-heat the incoming water increasing the efficiency of the boiler significantly.

In terms of function, conventional condensing and condensing-combi boiler systems are similar - both systems typically utilise gas to provide hot water and domestic heating. However, systematically there are some differences:

- Conventional condensing boiler systems typically see the installation of a hot water storage cylinder. Here, hot water generated in the boiler for domestic heating is used to heat water for domestic consumption - when needed hot water is then supplied to the user from the storage cylinder. Some systems may also include back up immersion heaters in case of boiler failure. 
- Condensing-combi boiler systems do not include a hot water storage cylinder - hot water for domestic consumption is instead generated within the boiler itself, on-demand. Within the boiler two heat exchangers exist - the larger, primary heat exchanger is used to generate domestic heating. A secondary heat exchanger exists to supply hot water on demand, this is done by diverting heated water from the domestic heating loop into the secondary heat exchanger to heat water for use in domestic consumption.

Both systems offer their own advantages, however condensing-combi boilers are more popular for reasons including: higher efficiencies, faster response to demand and compact designs (no storage tanks/cylinders). This higher efficiency is a significant driver for installation, and modern combi boilers are in the range of 92 to $94 \%$ efficient thermally for space heating (hot water heating is typically less efficient).

The main drawbacks for combi boilers are that if the boiler fails the household loses both hot water and heating systems and that combi boilers struggle to meet high demands for hot water (i.e. multiple draw points opened simultaneously). This second issue is more likely to be a problem for larger properties with many inhabitants, where demand for water is likely to be higher.

As mentioned above the compact design of combi boilers is seen as a major advantage, particularly for smaller homes. Figure 12 below shows the useable floor space available for English homes, as recorded in the housing survey [11], with a total of 23.95 million homes recorded.

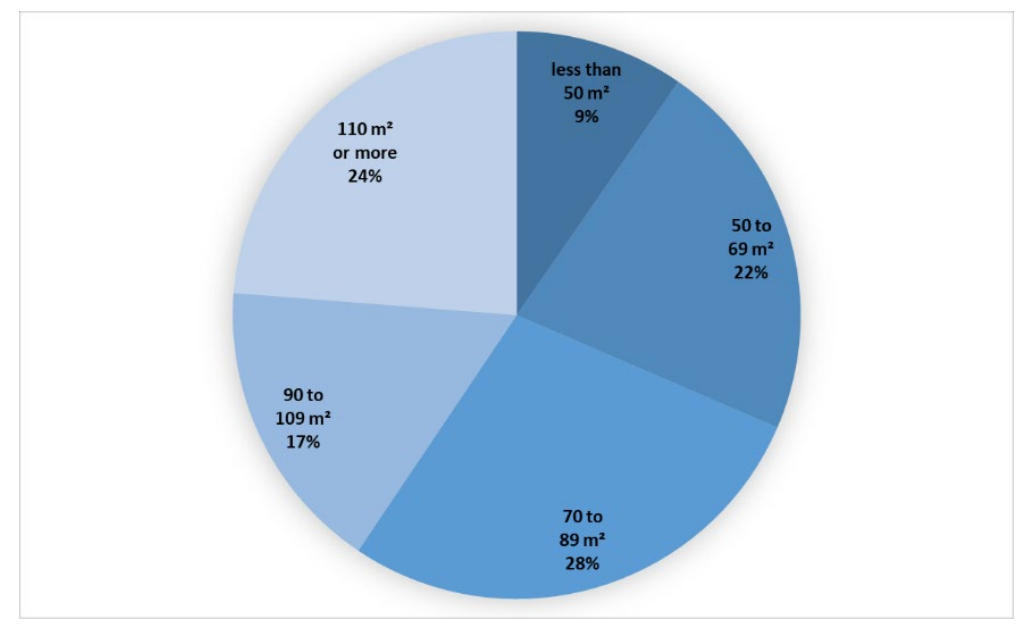

Figure 12 - Useable floor area in English homes 2017, data from [11]

For homes on the smaller end of the scale space should be considered at a premium and any alternative to existing technologies that requires a larger footprint may prove to be unpopular. Ultimately this is not to be considered in a quantitative manner in this study but is something that bears consideration in a qualitative manner.

\section{Highlighted Carbon Dioxide Utilisation Pathways}

**NOTE: This section should not be considered as a review of all alternative $\mathrm{CO}_{2}$ utilisation pathways, but as a brief introduction to a number of potential alternative technologies**

There are two distinct pathways in which $\mathrm{CO}_{2}$ could possibly be utilised which are discussed in this report: 
The first of these is carbon dioxide used as a chemical energy carrier where $\mathrm{CO}_{2}$ is transformed through chemical reaction to produce organic energetic molecules such as methane, longer chain hydrocarbons or other molecule such as methanol or DME. Given the existing infrastructure for natural gas, gaseous based fuels with a similar Wobbe index (the Wobbe index measures fuel gas interchangeability based on the parameter of HHV divided by the square root of specific gravity; 2 gases with identical indices would have identical heat output for the same device) would allow for the most seamless transition. Thus methane derived from $\mathrm{CO}_{2}$ could be considered. Modifications to burners and boilers in a range of properties (beyond just the domestic market considered here) would open up the availability of using other gases, but this would entail the undertaking of significant capital projects. Downsides to this route includes the need to generate hydrogen from low fossil sources which is typically associated with high operating costs.

Secondly, it is possible to use carbon dioxide without reaction in domestic heating technologies. In these technologies refrigerant-grade $\mathrm{CO}_{2}$ is used as a physical medium for heat transfer in devices such as heat pumps. In the UK, the national grid proposes, in its Future Energy Scenarios 2019 publication [12], the installation of at least 2.5 million heat pumps in domestic properties if the UK if the UK wishes to meet its 2050 "net zero" target. Given that $\mathrm{CO}_{2}$ heat pumps are available on the market it is feasible to believe that they could see significant deployment due to this. It should be noted that heat pumps do utilise electricity in their operation and that an increased demand for this may require changes to existing infrastructure. Beyond this, heat pumps have to be coupled with improved building heat efficiency due to the lower flow of heat (lower kW output) [8].

\section{Highlighted Non- $\mathrm{CO}_{2}$ Utilisation Pathways}

**NOTE: This section should not be considered as a review of all alternative non- $\mathrm{CO}_{2}$ utilisation pathways, but as a brief introduction to a number of potential alternative technologies**

Beyond the utilisation of $\mathrm{CO}_{2}$ there has been a focus on a number of pathways to minimise fossil $\mathrm{CO}_{2}$ emissions in the sector. Some of these alternatives are captured in the OFGEM report "The decarbonisation of heat" [8].

Electrification of the domestic heating sector has been proposed as an alternative to the current gas dominant market. Electricity is already the second most common fuel source for domestic heat, as shown in a prior section by the housing statistics. OFGEM [8] highlight two way in which electricity can be used to decarbonise heat can be used to reduce fossil carbon emissions in the sector:

1. Through the use of direct electric heating (as is already done in some properties)

2. Through the use of heat pumps, which have already been discussed above (non- $\mathrm{CO}_{2}$ heat pumps are available)

A shift to an increasingly electrified supply for heat does pose significant challenges to the existing grid and the likelihood is that significant capital work would need to be implemented to allow for this shift.

The use of CHP networks powered by non-fossil is also mentioned in the report, where the option to convert existing networks from gas powered to biomass fuelled is mooted alongside the construction additional networks/capacity. CHP systems offer an advantage of traditional power-only designs as they allow for the recovery of previously wasted heat energy, improving overall efficiency whilst adding increased value for the operator. It should be noted that CHP systems are typically capital intensive, and the installation of pipes to carry hot water is something that may prove to be difficult in areas where space is at a premium - with this being an issue both in terms of subterranean or the retro-fitting 
within existing buildings. Alternatively, CHP plants utilising natural gas could be installed along with carbon capture equipment allowing for utilisation or storage of the process $\mathrm{CO}_{2}$ - this would be significantly easier than trying to capture point-source $\mathrm{CO}_{2}$ in the near 27.5 million [5] households within the UK.

A further alternative would be to switch to a hydrogen grid. Significant projects have been funded at a research level, recently the HyDeploy [13] project began injecting hydrogen derived from low-carbon energy sources into the national grid for example. The H21 Leeds City Gate Project assessed the feasibility of operating a hydrogen grid within the UK, it was found that the increasingly common polyethylene pipes used in the gas distribution network are capable of safely transporting hydrogen, however other parts of the network would need to be replaced [8]. Given the difference in Wobbe indices of natural gas and hydrogen there is a need to retrofit or replace devices. An alternative to pure hydrogen would be the blending of hydrogen into natural gas, this would reduce the amount of $\mathrm{CO}_{2}$ emitted but would still likely see the government target missed without further intervention.

Considering all alternatives to current business as usual (BAU), both those that incorporate the use of $\mathrm{CO}_{2}$ and those that don't, it is clear to see that each proposed route offers significant challenges. Currently the most promising technologies are likely to include increased electrification (heat pumps or direct use of electricity), however both the identified technologies have significant drawbacks that warrant further investigation of these and alternatives to this. 


\section{Setting a Goal in Accordance with the Guidelines}

The guidelines [1] outline three common perspectives for TEA studies; described in the guidelines as follows:

Table 1 - Common TEA perspectives and their description, taken from [1]

\begin{tabular}{|l|l|}
\hline Perspective & Description \\
\hline R\&D & $\begin{array}{l}\text { Assessment of specific project(s) in research or development; either } \\
\text { identification of major barriers and drivers (hotspots) for a single } \\
\text { project or comparison of various projects }\end{array}$ \\
\hline Corporation & $\begin{array}{l}\text { Analysis of projects in development and deployment; assessment as } \\
\text { investment alternatives and comparison to existing processes; use of } \\
\text { detailed process data is common }\end{array}$ \\
\hline Market & $\begin{array}{l}\text { Analysis of projects in development and deployment stages; focus on } \\
\text { supply chains, effects of economic policy, the best use of resources or } \\
\text { the best way of obtaining a specific utility }\end{array}$ \\
\hline
\end{tabular}

This example will set goals in accordance to these perspectives, considering the common goal related questions associated with each that are captured in table 2 of the TEA guidelines (section B.3) with the domestic heating sector being the chosen backdrop. Each goal will be set in accordance with the guiding principles outlined in the guidelines document:

1. The goal shall state the study context including (if applicable) comparison to what, location, time horizon, scale and any involved partners

2. The goal shall state the intended application of the study and the reasons for carrying it out

3. The goal shall state the target audience

4. The goal shall state the commissioners and authors of the study

5. The goal shall state any limitations in usability from assumptions made or methods used

Before setting a goal it may be beneficial for the commissioner \& practitioner to consider from what perspective their study needs to be approached. Doing so may assist in identifying the correct contextual information (from market research) and identify expected key performance measures.

\section{Setting Goals from an R\&D Perspective}

TEA studies taken from the R\&D perspective are most likely to be used to assess emerging, lower TRL technologies with a common focus being on the identification of "hotspots" - i.e. major barriers or drivers to progress. This is reflected in the guidelines where common goal related questions (i.e. research questions) include: "what are major cost and value drivers?" and "what aspects need to be worked on(next)?" The low TRL is also typically characterised by greater uncertainty and ultimately the goal (and aims of the commissioner) should reflect this. The results of a R\&D study are unlikely to make a good basis for the business case of a FOAK plant - typically for this type of study is of more interest in determining cost-based indicators rather than profitability ones.

By providing answers to the typical goal questions exemplified above, TEA can support technology developers in identifying key areas of focus - or provide a useful, quantifiable answer as to why to end the current development process if the outcome suggests so. Major stakeholders in this perspective are likely to be technology developers and those involved in financing research efforts. 
The research questions above obviously do not meet the criteria outlined in the guidelines alone, and as such they need to be made more specific at the commencement of an assessment. To provide an example of this here an illustrative example is included below.

In the market overview section above one of the potential $\mathrm{CO}_{2}$ utilisation technologies mentioned was the transformation of $\mathrm{CO}_{2}$ into methane. Such a process offers a potential advantage over other mentioned alternatives as the Wobbe index of methane is very similar to natural gas - ultimately reducing the need to retrofit the gas distribution network and all gas burning devices across the UK. Conversion of $\mathrm{CO}_{2}$ into methane has been proven through various power to gas concepts [14][15], including so called power to gas processes (PtG) or other alternatives such as biogas upgrading. Currently most of these processes remain at a relatively low TRL and further work is needed to investigate their viability for deployment.

From this we can take the research question "what are major cost and value drivers?" and build a goal statement of sufficient detail:

The goal of this TEA is to investigate the major contributing elements to the production cost of methane from $\mathrm{CO}_{2}$ in a PtG technology, with the intention for the product methane to be injected into the current (2020) natural gas network within the UK. CapEx costs are derived based on the existing project pilotscale plant. The intention of the study is to identify major cost contributors for the benefit of future development. The target audience is the R\&D development team and the lead project engineer responsible for project development. This study is commissioned by the R\&D development team and is only to be used for the purpose of identifying economic impacts associated with current process performance.

The example goal addresses the associated research question, but expands upon this to include the necessary contextual elements and limitations. Any third party reader is given prior warning of the limitations (not suitable for comparison, CapEx is derived from a pilot plant and not a FOAK or NOAK full-scale plant). A successful study with this style of goal should be able to provide the target audience with a breakdown of elements contributing to production costs which can then be used as needed.

The research question "what aspects need to be worked on (next)?" can also be transformed into a suitable goal:

The goal of this TEA is to identify priority areas of process improvement for the specified PtG process for the production of methane from $\mathrm{CO}_{2}$ in the UK. Economic impact is assessed using current market costs (2020) for current performance and a theoretical best achievable performance in which thermodynamic, stoichiometric \& kinetic limits are respected with the intention of assisting the decision of prioritisation of research direction. The intention of the study is to identify priority areas for assisting in decisions on future development priorities. The target audience is the R\&D development team and the lead project engineer responsible for project development. This study is commissioned by the R\&D development team and is only to be used for the purpose of identifying economic impacts associated with current process performance.

As with the prior example above, the intent of the research question is captured within the goal statement augmented by the additional requirements specified in the guidelines but is augmented by additional details. Successful studies undertaken with this type of goal should be able to assist in determining specific aspects of the process for development in increasing deployment feasibility e.g. through identify areas to decrease production cost. 
It should be noted that deployment feasibility does extend beyond pure financial considerations. Considering the domestic heating sector once again the market research indicates that current combiboilers offer the advantage of only requiring a small footprint, with this being especially useful when considering that a large percentage of UK homes were shown to have limited living space. Replacing this technology with an alternative, such as a heat pump, may require the occupation of more space making this a less appealing alternative for a customer. Thus it may be beneficial to identify developments that can both improve performance (reduce cost) and reduce the footprint of the technology - although quantifying the importance of this may be challenging (but even qualitative reasoning may be seen as a benefit).

Alongside addressing hotspots for a singular process it is possible to conduct TEA studies of a broader scope from this perspective. The goal example for this listed in the guidelines is for assisting in decision making in funding programmes, answering questions such as "which $\mathrm{CO}_{2}$ utilisation project should we fund"? The breadth of this horizon-scanning type goal can vary, the comparison can be broad across numerous distinct technologies (e.g. heat pumps or hydrogen production?) or significantly narrower in only considering distinct options within a technology (e.g. ground source or air source heat pumps? Iron or cobalt based catalysts for a given PtX process?). Such approaches may be useful to undertake when research budgets are limited and there is a need to identify the most promising option for immediate focus.

The goal of this TEA is to aid the decision of determining which catalyst class should be selected for further investigation for a $\mathrm{CO}_{2}$ methanation process with the long-term goal of deployment to the UK domestic heating sector. Two broad classes of catalyst are assessed: noble metal catalysts and nickel catalysts, with current laboratory performance (2020) used as the basis for viability. Costs are derived from 2020 data where applicable. Catalyst performance is assessed via the simulation of a $500 \mathrm{t} / \mathrm{year}$ of methane plant using ASPEN+ and comparisons of performance should be limited to within this study. The intention of this study is to support decision making on catalyst selection. The target audience and commissioner of this study is the R\&D funding manager, the study authors are the R\&D team. This study should not be used comparatively and third party readers should not its use of simulation data.

As before the study context is made clear, any third party encountering the study can clearly ascertain what is being compared and the basis of this. The limitations of the study (simulation on a small scale, not to be used for further comparison) are also made clear.

\section{Setting Goals from a Corporation Perspective}

TEA studies conducted from a corporation perspective typically focus on projects/processes further along the research-development-deployment cycle - predominantly the latter two stages. These studies are usually characterised by more certainty in the technologies technical performance, even if questions may remain around potential profitability.

This focus on profitability is reflected in the guidelines by the two goal examples that are provided: determining whether there is a viable business case and economic due diligence for investment in a start-up. Common goal related questions provided by the guidelines include:

- "How does the $\mathrm{CO}_{2}$ utilisation product perform against current and upcoming benchmarks?"

- "Is the $\mathrm{CO}_{2}$ utilisation product economically viable in a current or future scenario?"

When considering profitability metrics from this perspective the focus is likely to be in answer to "what is the profitability of my particular part of the entire supply chain?" With this being contrasted by the 
potentially broader concerns of the market perspective, where the study may focus on the whole supply chain for one technology or take a wider view of the whole market.

As before, these highlighted questions alone do not provide enough context and detail to fulfil the requirements and additional details are required. Expanding the first example into an example goal gives:

The goal of this TEA is to assess whether there is an existing business case for the installation of a $\mathrm{CO}_{2}$ heat pump in place of a new combi-boiler (existing market standard) in 2020, with both technologies having an assumed 20-year life span. Capital costs for installation are based on 2020 values and lifetime operating and maintenance costs are based on predicted cost trends and varied in the scenario analysis. The installation is in the UK and the technology is sized to fit daily and seasonal usage patterns, scaled to meet a UK-average TDCV for gas equivalent heat energy delivered. The intention of the study is to demonstrate the potential profitability of the $\mathrm{CO}_{2}$ utilisation technology. This study is conducted by a third-party practitioner and was commissioned by the $\mathrm{CO}_{2}$ utilisation technology developer. The target audience is the senior management team and investors of the technology developer. This study can be used for comparatively by third parties - no other limitations are identified.

For the example profitability for the technology holder is expected to be impacted by whole-life service cost for the customer - hence a gate to gate study undertaken from the customer's perspective. Such a study allows for the company to determine what is feasible in terms of a market price for their own technology and this can ultimately be used within their own profitability calculations.

This approach may differ from the typical gate to gate TEA studies undertaken around a company's own production process. For example, a goal can be set for determining potential profitability by finding a minimum selling price for methane produced from $\mathrm{CO}_{2}$ akin to the examples considered above with this being something more commonly seen. This broad differing approach shows the diversity of situations to which TEA studies can be applied to answer or assist in answering research questions.

\section{Setting Goals from a Market Perspective}

TEA studies conducted from a market perspective are similar to those undertaken from a corporationperspective in that they typically focus on technologies in development or deployment stages. The guidelines describe these studies as having a focus on supply chains, the effects of economic policy, the best way of obtaining a specific utility or for identification of the best use of resources. This description suggests a broader approach than the corporation one above, showing where a divergence in the perspectives arises. The goal examples listed in the guidelines includes: investigating local $\mathrm{CO}_{2}$ supply chains (possibly to identify potential sources of profitable innovation through industrial symbiosis), identifying the best use of limited resources such as $\mathrm{CO}_{2}$ streams, renewable electricity \& $\mathrm{H}_{2}$ and assessment of policy and regulations. The common goal related questions given in the guidelines are:

- What are current states, favourable conditions, best practices and necessary actions for regional $\mathrm{CO}_{2}$ utilisation value chains?

- What regulatory clarification and support (type, timing \& budgets) is required for specific $\mathrm{CO}_{2}$ utilisation products/service groups?

These questions are notably different in scope to those shown previously, and are arguably less common than the goals discussed in the sections above. 
Relating this type of research question to the UK domestic heating sector, the following can be proposed:

- Is it more beneficial for a government to invest capital into heat pumps or into converting the gas network for hydrogen utilisation? Which will result in the lower costs for domestic customers?

- Would the implementation of an emissions tax on domestic gas fuels significantly increase the viability of low-fossil alternatives?

- What level of investment would be required to transform the electricity grid to allow for electrification of the domestic heating sector?

Once again these questions do not meet the requirements of the guidelines and as such need to be expanded upon. An example is given below:

The goal of this study is to determine which type of regulatory support would best provide assistance to the deployment of $\mathrm{CO}_{2}$-derived methane in place of natural gas in the UK gas grid with the intention of replacing all natural gas before the year 2035. The production of methane in PtG technologies is the chosen pathway for methane production, with a range of energy efficiencies and production costs considered. Scenarios considered include: the use of capital support for PtG system construction and the implementation of an elevator-style increasing tax on natural gas use. This TEA study is authored by a third party practitioner and was commissioned by a political think-tank, with the intended audience being policy makers at a national level. The intention of the study is to assist in lobbying support for the most economically feasible policy for implementation. This study can be utilised in comparisons but is limited by the accuracy of the data used. 


\section{Inventory Impacts on Goal Achievement: Advice for Using Existing Studies or Inventories for New Goals}

Note: This section is written primarily from the perspective of utilizing an existing study to achieve the aims/goals outlined in a new project. However, many of the considerations can also be of use for stakeholders looking to produce a new study given that the focus is primarily around inventory sensitivity.

In both the guidelines document and this worked example it is acknowledged that the success of achieving a specified TEA goal can be impacted by the inventory data available. Commissioning and conducting a new study comes with the obvious advantage of allowing for the practitioner to control the inventory used to ensure that the goal is met. Alternatively, using an existing study allows for the saving of valuable resources for the sacrifice of this flexibility.

Should the decision be made to use, or investigate the possibility of using, an existing study (or studies) care should be taken to ensure that the study is fit for purpose. Ultimately the outcome of such an investigation is subjective, with only the stakeholders capable of determining what level of deviation between a target goal and an existing study is acceptable. For example, utilising an existing study based on a similar technology but applied in a different geographical location for a similar goal may introduce an acceptable level of uncertainty earlier in the R\&D cycle but is unlikely to meet the requirements of due diligence during the deployment phase of a FOAK plant.

Even in cases where the utilisation of an existing study is feasible care should be taken to ensure both the veracity of the study and that the level of uncertainty introduced is indeed acceptable. To assist stakeholders and third parties in this type of assessment this section proposes a simple strategy to mitigate the pitfalls identified earlier.

It is possible to consider elements of a TEA inventory as having one or both a "technical" component and an economical component:

- A technical component can be characterised as being typically displayed in the form of quantity/functional unit of the study e.g. $500 \mathrm{~kg}$ of $\mathrm{CO}_{2} / \mathrm{t}$ product or $500 \mathrm{kWh}_{\mathrm{e}} / \mathrm{t}$ product. This component is derived from the technical performance of the technology/plant (real or imagined such as stoichiometric minimum inputs used to give an artificially high conversion efficiency)

- An economical component can be characterised as having a unit cost e.g. $€ 60 / t \mathrm{CO}_{2}$ or $€ 22.30 / \mathrm{MWh}_{\mathrm{e}}$. This component is derived from unit costs in the relevant location at the time of the study

It is improbable to find an existing study in which all inventory data, both technical \& economical, will align exactly with the requirements of a different goal. As such there is a need to determine which elements of the inventory are most impactful in the existing study with regards to overall performance.

A natural place to begin investigating this would be the sensitivity analysis of the existing study. Also of interest, if present, should be the global sensitivity analysis and uncertainty analysis which can provide further indication of confidence levels in the outcomes of the study and the quality/reliability of the input data itself. 
Most, but not all, TEA studies are likely to include a local (single-factor) sensitivity study around a cost (unit production cost, MSP) or profitability (NPV, IRR) or general performance metric which can help identify input components which have the largest impact on the calculated output factors/measures. Examples of two common graphs showing sensitivity are shown in figure 13 below.
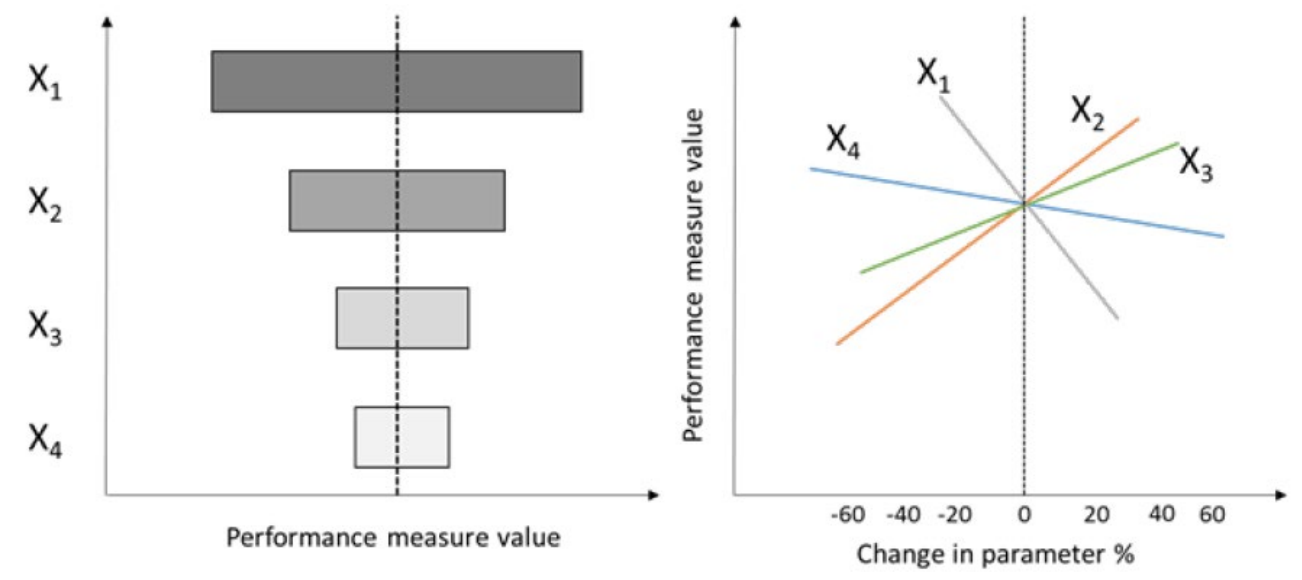

Figure 13 - Examples of local sensitivity analysis charts: tornado graph (left) and line graph (right), from [1]

The tornado graph shows the impact on production cost by varying each factor (typically by a set value such as $\pm 10 \%$ ) with the wider bars indicating a greater sensitivity to the identified parameter. The line graph shows the impact on the performance measure value through changes in the gradient of the line - a steeper gradient shows a greater sensitivity to the identified factor (parameter).

Identification of the most sensitive factors is beneficial when assessing the feasibility of utilising an existing study. If there is significant divergence in sensitive inputs, when comparing the existing study to those that would be used in a new study, then caution should be taken when deciding to utilise this.

When considering what would cause these divergences in sensitive input data there are numerous elements to consider, but the most common are likely to be locational, temporal or "scale-related" variance.

Temporal variation of inventory data relates to the change of economic and technical aspects over time. Economically, unit prices for inventory inputs can be expected to vary over time. In some cases, for example energy vectors, prices variance can be significant over a relatively short period of time or in some cases the rate of change may be lower reducing the impact (e.g. labour costs). Figure 14 below demonstrates how volatile some prices may be, by showing the monthly average day-ahead contract gas price for the UK over a 10-year span. Wholesale or large-scale purchasers are unlikely to use dayahead contracts and so the actual level of volatility is likely to be lower but the graph clearly shows significant variance. 

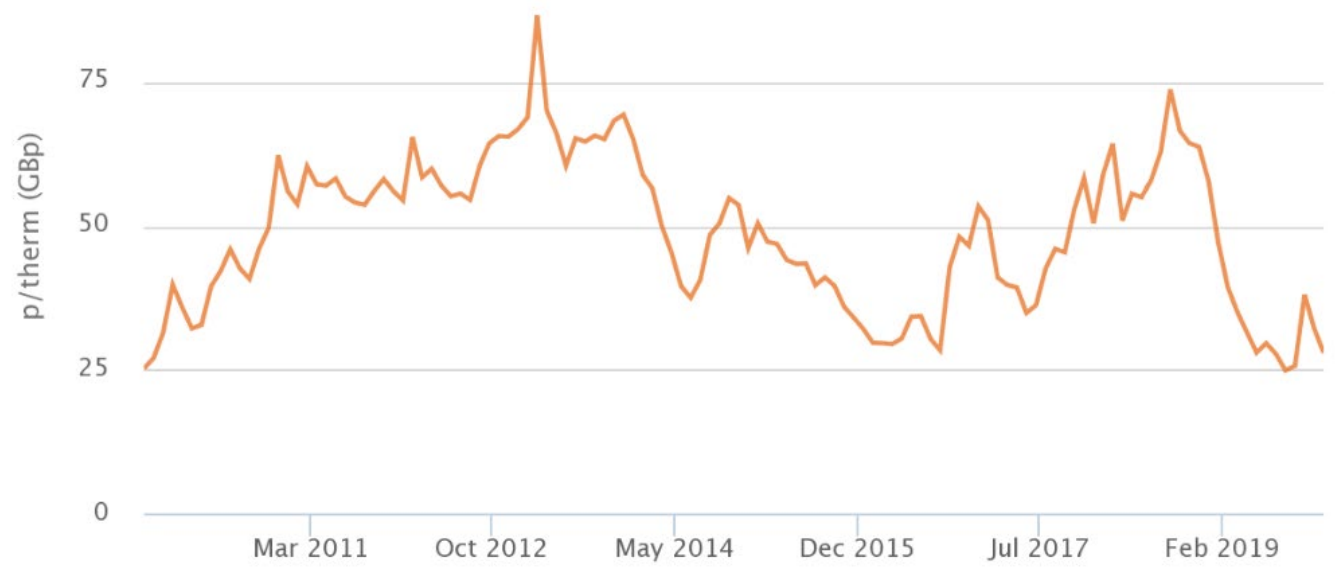

Figure 14 - UK day ahead contract natural gas price: monthly average October 2009 to Jan 2020, taken from [16]

When considering technological performance, it is generally expected that emerging technology classes (or classes of technologies under intense research focus) will improve their performance over time. Retrospectively the validity of this for a given technology can be examined by investigating published performance data over time [17], alternatively future predictions can be made through consulting experts in the area [18]. In either case, using an outdated study could result in issues if technical performance is not compared.

Scale related variance can impact technical performance (the performance of a pilot plant may not reflect that of a scaled up NOAK plant for example) but is more likely to impact economic data. Scale here refers to the scale at which the unit cost was derived for the use in the study - ultimately there are significant unit cost differences when buying in bulk at free on board (FOB) price when compared to small quantities from general chemical suppliers. It is generally advised to avoid the use of studies based on the latter, as any calculated factors are likely to be wildly inaccurate and ultimately of little use for deriving costs of delivery to market on an appropriate scale. Figure 15 shows an example of how scale can impact price, by showing the EU28 average electricity price per kWh [19] for industrial consumers (not including taxes, levies or reductions). Each band corresponds to a different usage level:

- Band IA: Consumption < $20 \mathrm{MWh}$

- Band IB: $20 \mathrm{MWh}<$ Consumption < $500 \mathrm{MWh}$

- Band IC: $500 \mathrm{MWh}<$ Consumption < $2000 \mathrm{MWh}$

- Band ID: $2000 \mathrm{MWh}<$ Consumption < $20000 \mathrm{MWh}$

- Band IE: $20000 \mathrm{MWh}<$ Consumption < $70000 \mathrm{MWh}$

- Band IF: $70000 \mathrm{MWh}<$ Consumption < $150000 \mathrm{MWh}$

- Band IG: Consumption > $150000 \mathrm{MWh}$ 


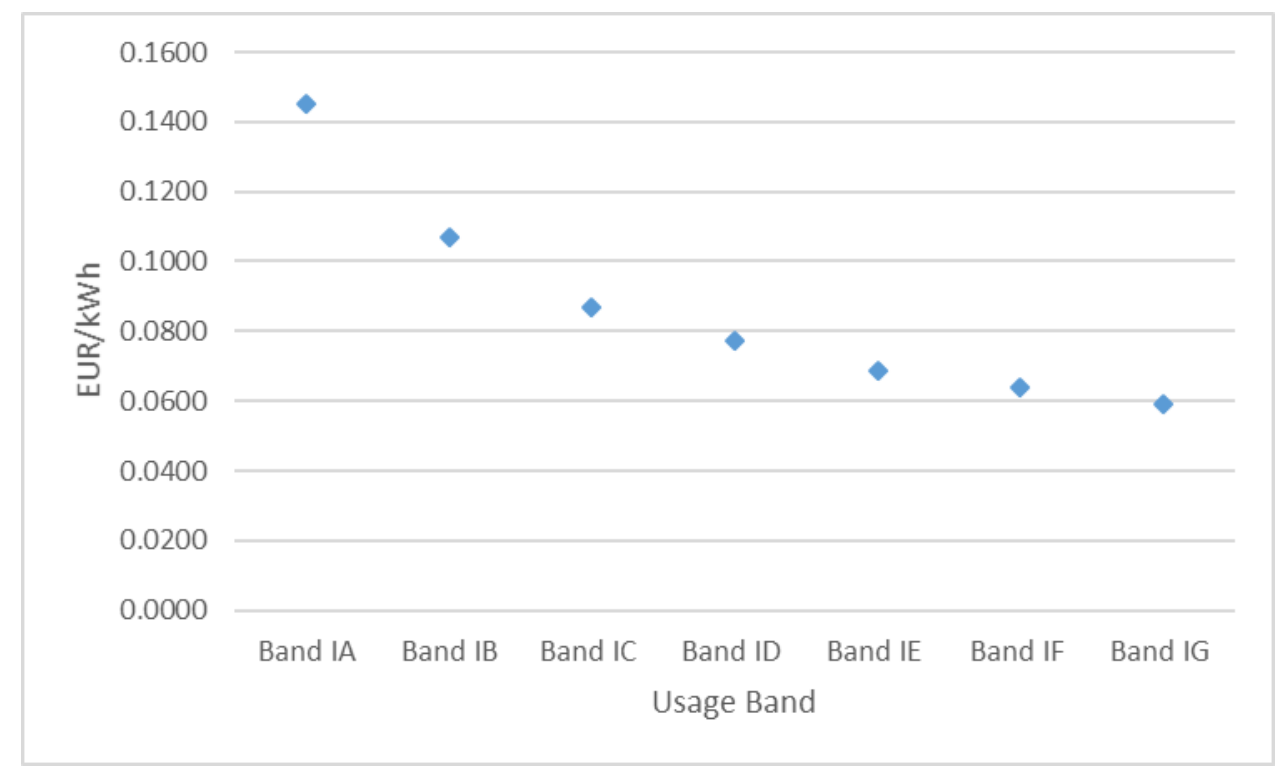

Figure 15 - price per kWh for electricity and variance with band usage (2019 Q1 \& 2 figures) [19] - EU28 average

Figure 15 clearly shows how the unit prices decreases significantly - in any electricity intensive process, such as electrolysis to produce $\mathrm{H}_{2}$, the impact of using the band IA price in place of the band IG is notable.

Locational variation accounts for technical/economic component variation due to geographical location. Here, it is expected that most variation will be accounted for in economic components but some variation may be found in relation to performance. For example, geographic locations have differing mean average temperatures which can impact the energy needed for heating and cooling, local regulations may require specific safety features (for regulatory requirements) that impact capital cost.

However, variation on cost components are more likely to have a significant impact on output cost metrics. Figure 16 below shows the variation of electricity prices for various bands across a number of European countries. Once again, a significant level of variance is shown dependent on band and on location. 


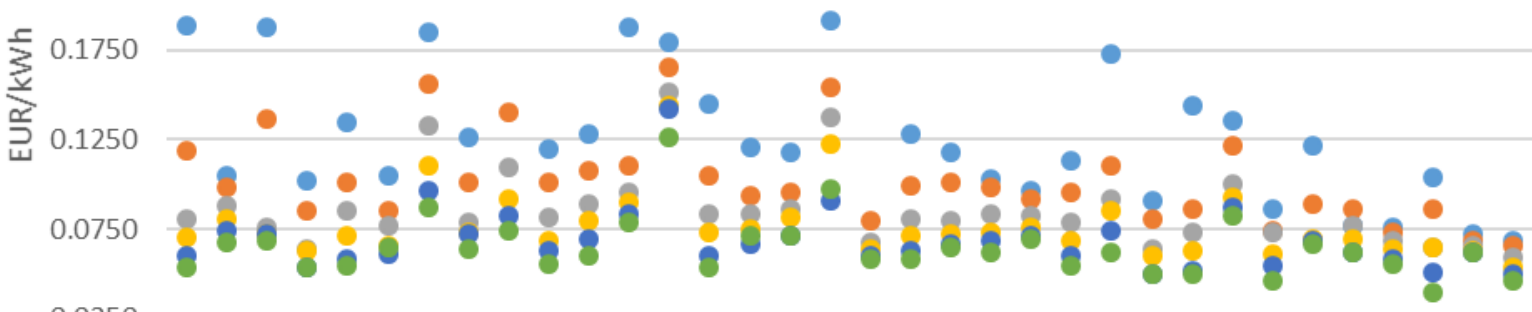

0.0250

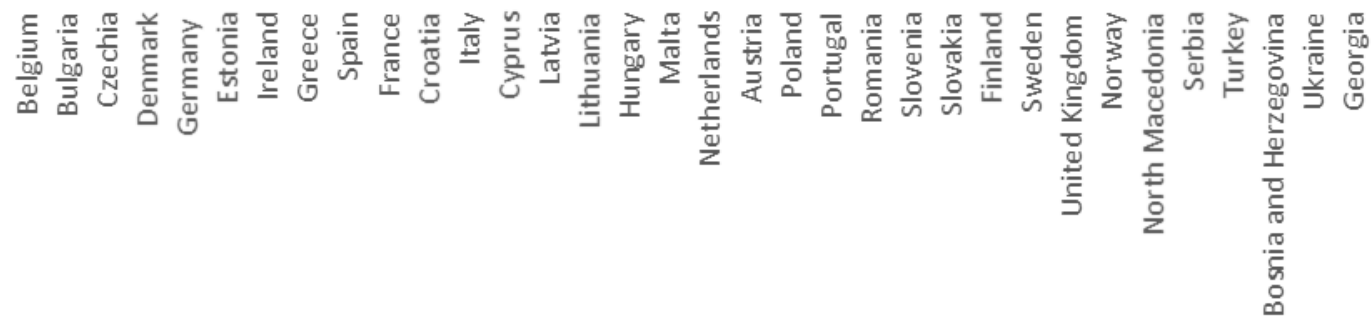

- Band IA B Band IB B Band IC B Band ID • Band IE • Band IF

Figure 16 - Price per kWh for electricity and variance with band usage (2019 Q1 \& 2 figures) [19] - various countries

A focus on electricity prices is relevant for this worked example given the potential to replace existing natural gas supplies with PtG derived fuels - either hydrogen or methane (produced from $\mathrm{CO}_{2}$ and $\mathrm{H}_{2}$ ). As shown in the previous worked examples in this project hydrogenation of $\mathrm{CO}_{2}$ to produce hydrocarbons sees the vast majority of the costs attributed to the operating costs of the electrolyser; with this being dominated by the cost of electricity.

Whilst only the commissioner, practitioner and other relevant stakeholders can ultimately make the decision to utilise an existing study (and the associated risk that arrives with this) it should be considered prudent to complete the necessary due diligence by considering, as a minimum, the factors outlined above.

To demonstrate how impactful this can be figure 17 is included showing overall production cost for hydrogen utilising varying input conditions for a proposed $4 \mathrm{MW}$ system. Performance and economic data for PEM and alkaline (ALK) electrolysers is taken from source [20], data is provided for existing (2017) performance and expected future (2025) performance for both electrolyser types. This is combined with 2019 P1 (Q1 \& 2 average figures) electricity prices from various European locations (same band, but including local taxes \& levies) to provide the estimations shown in the figure. 


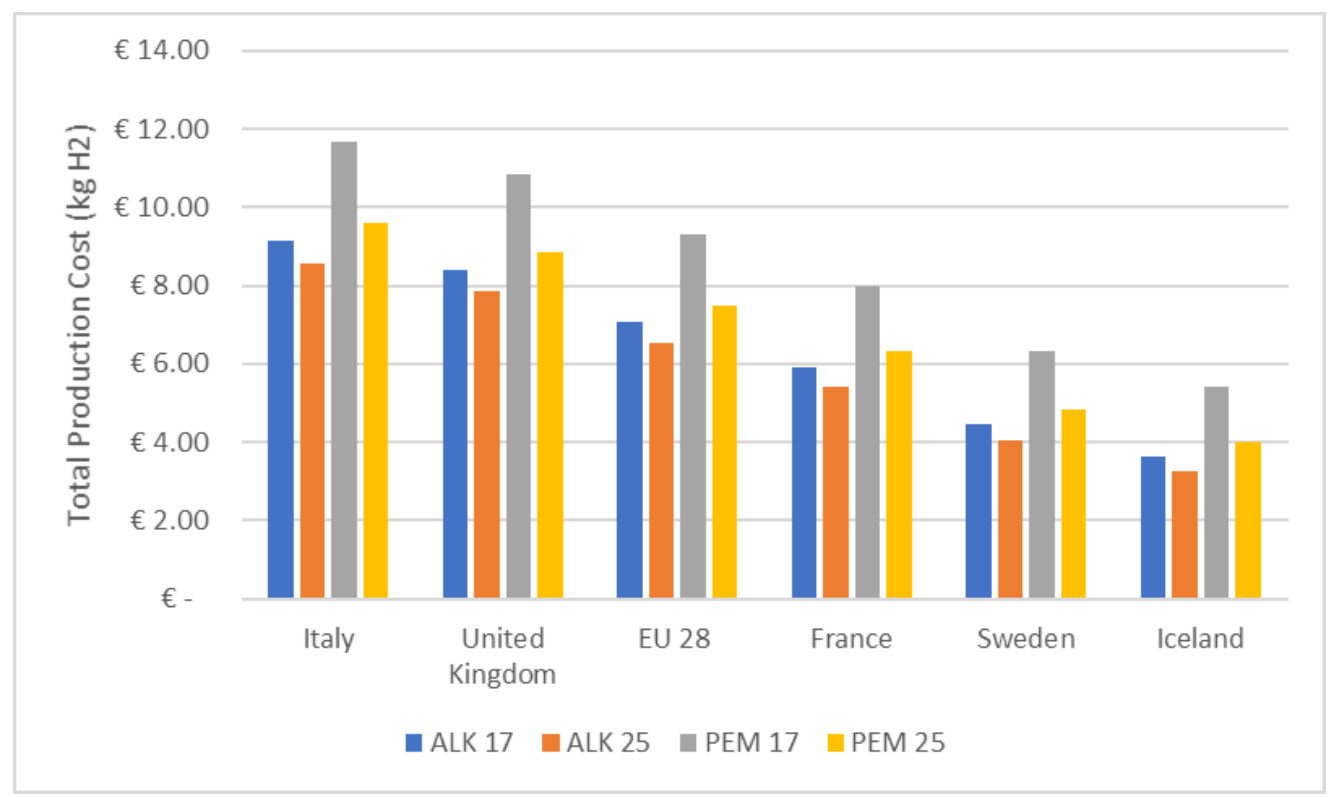

Figure 17 - estimated production cost for hydrogen with locational and temporal variance

The graph shows significant variance on estimated production cost with locational variance due to the changes in electricity price. Some variance is also shown due to temporal variance, with this being particularly profound for PEM electrolysis. This is likely due to the fact that currently PEM is the less mature technology, with more scope for technological improvement. Whilst these figures only provide rough estimates (that should not be quoted elsewhere) they can be used to highlight the need for caution when utilising existing scenarios/studies. Ultimately, figure 17 shows that costs, and potentially profitability are impacted by greatly by contextual information - decisions made on the incorrect context can potentially lead to undesired outcomes. 


\section{Conclusions}

- Goal setting should be considered as part of an iterative process, one that involves (a minimum of) both the study commissioner and the practitioner. Such an approach can help ensure that the aims of the commissioner can be met or adjusted, even in the face of procedural issues such as a lack of required inventory data.

- A simple research question in itself does not make a good goal, as they typically lack the detail required for effective communication of the study's intent (potentially problematic for the all parties from the commissioner to the practitioner to the intended (\& wider) audience. Adding contextual information (as outlined in guideline B3) can assist in avoiding this pitfall. Efforts should be made by all study authors to ensure that the goal communicates the studies intention clearly with the correct context.

- TEA studies can be considered from a range of perspectives, with this likely impacting what are the major focus points of the study. This doesn't mean that a study taken from one perspective cannot be of use or interest to a given stakeholder of another perspective but care should be taken when extrapolating results for use outside of the initial goal/scope.

- If the commissioner intends to utilise an existing study, checks should be made to ensure that the results of the study are indeed of an appropriate standard for use in place of commissioning a new study. Studies can be considered as being sensitive to both economic and technological changes. Care should be taken to consider variance (identified in this study as temporal, locational and scale-based - although this shouldn't necessarily be considered as an exhaustive list) and its potential impact on the usability of any results. 


\section{References}

[1] A. Zimmerman et al., "Techno-Economic Assessment \&amp; Life-Cycle Assessment Guidelines for CO2 Utilization," 2018. doi: 10.3998/2027.42/145436.

[2] IEA, "The Future of Hydrogen for G20," 2019. [Online]. Available: https://www.iea.org/reports/the-future-of-hydrogen.

[3] Committee on Climate Change, "Net Zero: The UK's contribution to stopping global warming," 2019. [Online]. Available: https://www.theccc.org.uk/publication/net-zero-theuks-contribution-to-stopping-global-warming/\%0Awww.theccc.org.uk/publications.

[4] BEIS, “DUKES 2019," 2019. [Online]. Available: https://assets.publishing.service.gov.uk/government/uploads/system/uploads/attachment_d ata/file/840015/DUKES_2019_MASTER_COPY.pdf.

[5] National Statistics, "Energy Consumption in the UK ( ECUK ) 1970 to 2018," 2019. [Online]. Available:

https://assets.publishing.service.gov.uk/government/uploads/system/uploads/attachment_d ata/file/820843/Energy_Consumption_in_the_UK_ECUK_MASTER_COPY.pdf.

[6] J. Palmer and I. Cooper, "Housing Energy Fact File, Department of Energy and Climate Change (DECC)," 2013. [Online]. Available:

https://assets.publishing.service.gov.uk/government/uploads/system/uploads/attachment_d ata/file/345141/uk_housing_fact_file_2013.pdf\%0Ahttps://www.gov.uk/government/upload s/system/uploads/attachment_data/file/345141/uk_housing_fact_file_2013.pdf.

[7] BEIS, "Energy Trends: UK Gas," 2020. https://www.gov.uk/government/statistics/gas-section4-energy-trends.

[8] Ofgem, "The Decarbonisation of Heat," 2016. [Online]. Available:

https://www.ofgem.gov.uk/system/files/docs/2016/11/ofgem_future_insights_programme_ -_the_decarbonisation_of_heat.pdf.

[9] Energy Savings Trust, "Measurement of domestic hot water consumption in dwellings," Energy Savings Trust, 2008.

https://www.gov.uk/government/uploads/system/uploads/attachment_data/file/48188/314 7-measure-domestic-hot-water-consump.pdf.

[10] OFGEM, "Typical Domestic Consumption Values," 2020. https://www.ofgem.gov.uk/gas/retail-market/monitoring-data-and-statistics/typicaldomestic-consumption-values.

[11] Ministry of Housing Communities and Local Government, "English Housing Survey 2018-19 Headline Report," 2020.

https://assets.publishing.service.gov.uk/government/uploads/system/uploads/attachment_d ata/file/860076/2018-19_EHS_Headline_Report.pdf.

[12] National Grid, "Future Energy Scenarios 2019," Future Energy Scenarios, 2019. http://fes.nationalgrid.com/media/1409/fes-2019.pdf.

[13] ITM Power Limited, "HyDeploy: UK Gas Grid Injection of Hydrogen in Full Operation," 2020. https://www.itm-power.com/news/hydeploy-uk-gas-grid-injection-of-hydrogen-in-fulloperation. 
[14] A. Sternberg and A. Bardow, "Life Cycle Assessment of Power-to-Gas: Syngas vs Methane," ACS Sustain. Chem. Eng., vol. 4, no. 8, pp. 4156-4165, 2016, doi:

10.1021/acssuschemeng.6b00644.

[15] M. Bailera, P. Lisbona, L. M. Romeo, and S. Espatolero, "Power to Gas projects review: Lab, pilot and demo plants for storing renewable energy and CO2," Renew. Sustain. Energy Rev., vol. 69, no. October 2016, pp. 292-312, 2017, doi: 10.1016/j.rser.2016.11.130.

[16] OFGEM, "OFGEM - All wholesale gas charts and indicators," 2020.

https://www.ofgem.gov.uk/data-portal/all-charts/policy-area/gas-wholesale-markets.

[17] L. Bertuccioli, A. Chan, D. Hart, F. Lehner, B. Madden, and E. Standen, "Study on development of water electrolysis in the EU, Fuel Cells and hydrogen Joint Undertaking," 2014. [Online]. Available: https://www.fch.europa.eu/sites/default/files/FCHJUElectrolysisStudy_FullReport (ID 199214).pdf.

[18] O. Schmidt, A. Gambhir, I. Staffell, A. Hawkes, J. Nelson, and S. Few, "Future cost and performance of water electrolysis: An expert elicitation study," Int. J. Hydrogen Energy, vol. 42, no. 52, pp. 30470-30492, 2017, doi: 10.1016/j.ijhydene.2017.10.045.

[19] EUROSTAT, “EUROSTAT Electricity Prices (Table NRG_PC_205)," 2020. https://appsso.eurostat.ec.europa.eu/nui/show.do?dataset=nrg_pc_205\&lang=en.

[20] IRENA, "Hydrogen From Renewable Power: Technology outlook for the energy transition," 2018. [Online]. Available: https://www.irena.org/-

/media/Files/IRENA/Agency/Publication/2018/Sep/IRENA_Hydrogen_from_renewable_powe r_2018.pdf.

[21] BEIS, "UK becomes first major economy to pass net zero emissions law," 2019. https://www.gov.uk/government/news/uk-becomes-first-major-economy-to-pass-net-zeroemissions-law.

[22] Z. Hausfather, "Analysis: Why the UK's CO2 emissions have fallen 38\% since 1990," 2019. https://www.carbonbrief.org/analysis-why-the-uks-co2-emissions-have-fallen-38-since-1990. 